\title{
Kinematic Investigation, of a New Flexible Orthopedic Screw (FlexyScrew) for Repairing the Torn Scapholunate Ligament, with the Use of 3D-CT/Scan-Covariant Method and Demonstration on a 3D-Printed Model
}

\author{
Fotios Vasilios Nikolopoulos ${ }^{*}$, Nikos Charalampos Efthymiadis ${ }^{2}$ and Vassilios Antonios Kefalas ${ }^{2}$ \\ 'Department of Orthopaedics, General Hospital of Piraeus "Tzanio", Zani \& Afentouli 1, Piraeus 18536 Greece \\ 2School of Applied Mathematical \& Physical Sciences, Section of Mechanics, Nat. Technical University of Athens, H. Polytechniou 9, Zografou, 15780 \\ Greece
}

*Corresponding author: Fotios Vasilios Nikolopoulos, Department of Orthopaedics, General Hospital of Piraeus “Tzanio", Paligenesias 40, Peristeri, Athens, Greece; Tel: +306936000618; Fax: +302110199657; Email: nikoped@gmail.com

Received: December 12, 2018; Accepted: December 19, 2018; Published: December 20, 2018;

\begin{abstract}
Kinematic analysis with the use of 3D-CT/scan-reconstruction and covariant analysis gives the ability to have a detail kinematic prescription of the Scaphoid and Lunate bones and further of the Scapholunate joint when the wrist gets the extreme positions. This analysis can be used in the design criteria for the development of a new type screw FlexyScrew.

Data obtained from the 3D-CT/scan-reconstruction and the use of covariant analysis give a detail kinematic analysis of the Scaphoid and lunate bones. This data was used as the technical guidelines for constructing the FlexyScrew. Further a 3D-printed model of the Scapholunate joint which is based on the above analysis simulate the conditions in which the FlexyScrew can operate.

It was verified, that insertion of the FlexyScrew in the appropriate position does not disturb the 3D joint movement between the Scaphoid and Lunate bones. Moreover the spring of the Flexyscrew allows the relative motion, translation and rotation, of Scaphoid and Lunate bones and generally can follow in a satisfactory way the movements of the joint.

The insertion of the FlexyScrew seems to offer a good alternative method for the difficult and problematic carpal Scapholunate surgeries. This simple kinesiological method of analysis with the appropriate flexible screw can be applied also to other unstable joints, caused by ligamentous injuries, for example replacing the torn Anterior Cruciate Ligament in the knee joint.
\end{abstract}

Keywords: FlexyScrew, Orthopaedic, CT/scan, Scapholunate, Spring, Ligament

\section{Introduction}

The Scapholunate (Sc-L) joint is of major importance to the kinematics of the wrist, the injury of which can lead to radiocarpal dislocations or fractures- dislocations [1] and subsequently to the dissociation of the SL ligament and the instability of the carpus [2].

Various surgical methods which use autografts (tendons, articular capsules etc) have been proposed for the rehabilitation of the Sc-L joint instability and prevention of SLAC. Except for these methods, several types of implants, that are currently available, are used in procedures similar to RASL procedure [3] and various types of orthopaedic screws have been developed for Sc-L instability. Herbert Whipple screw (Herbert/Whipple, 2008) which is placed through scaphoid and lunate bone was developed [4] for the treatment from Sc-L ligament injury [5], SLIC screw joining scaphoid and lunate, was also proposed [6] and a prototype screw with helical coil cut design using solid screw from Zimmer ${ }^{\circledR}$ was developed by Helical Products Company Inc [7].
In previous work, we have already presented a new orthopaedic screw [8-11] named FlexyScrew (FS), because of its unique characteristic flexible middle spring portion. The FS is intended to repair the Sc-L unstable joint with a simple surgical technique for insertion and novel removal [12]. FS is based on a general biomechanical concept and potentially could be used on a number of other unstable joints with torn ligaments, like the anterior cruciate knee ligament, with the appropriate design modifications.

The insertion of the FS in the S-L joint should ideally substitute the function of the torn ligaments and restore fully the dynamics and kinematics of the joint. We have already studied the biomechanical forces of the Sc-L ligament complex [13] for the spring stiffness constant specifications of the FS. In addition to the stability that it must provide to the Sc-L joint, the FS must also cover the kinematics in the extreme positions of the wrist, flexion-extension and radioulnar deviation. 
Fotios Vasilios Nikolopoulos (2018) Kinematic Investigation, of a New Flexible Orthopedic Screw (Flexyscrew) for Repairing the Torn Scapholunate

Ligament, with the Use of 3D-CT/Scan-Covariant Method and Demonstration on a 3D-Printed Model

This work aims at studying the behavior of the FS via the kinematic analysis of the Sc-L joint, demonstrating the effectiveness and the functionality of the screw, in a 3D-printed model replicating the exact anatomic characteristics of the bones and the screwed joint.

In the present analysis we adopted the matrix method for the kinematic representation, considered as better applied in voxelized bone-data. We performed kinematic analysis in the neutral and all four extreme positions of the wrist using CT/scan and $3 \mathrm{D} /$ reconstruction of the scaphoid and lunate bones. By using co-variant analysis on bone data, we obtained the centroids and three principal axes for the Sc and $\mathrm{L}$ in the neutral and the four extreme positions of the wrist.

\section{Methods and Materials}

The healthy wrist of one of the authors, a male of 50 years old, was offered to be subjected to a CT/scan, with a General Electric, model Optima CT/660 tomograph. The scan was performed in four extreme positions of the wrist figure 2 flexion-extension, radio-ulnar deviation and in neutral as a reference position.

\section{Sc-L Kinematic}

The tomographic data (dicom file), from the CT scan, was analyzed with the help of the open code (3D Slicer), and the stereolithographic (STL) files obtained from the voxelized volume of Sc and L, were isolated with the method of Region of Interest (ROI) as shown in figure 3.

Suitable code was also developed, based on the open source code Octave@, for reading the STL bone files and for obtaining the centroid and the principal axis system for each bone using covariant matrix transformations. Principal axis directions and the centroid coordinates are characteristic and unique for each bone mass distribution in the 3D-space Figure 1 and therefore can be used to follow the motion of the bones.
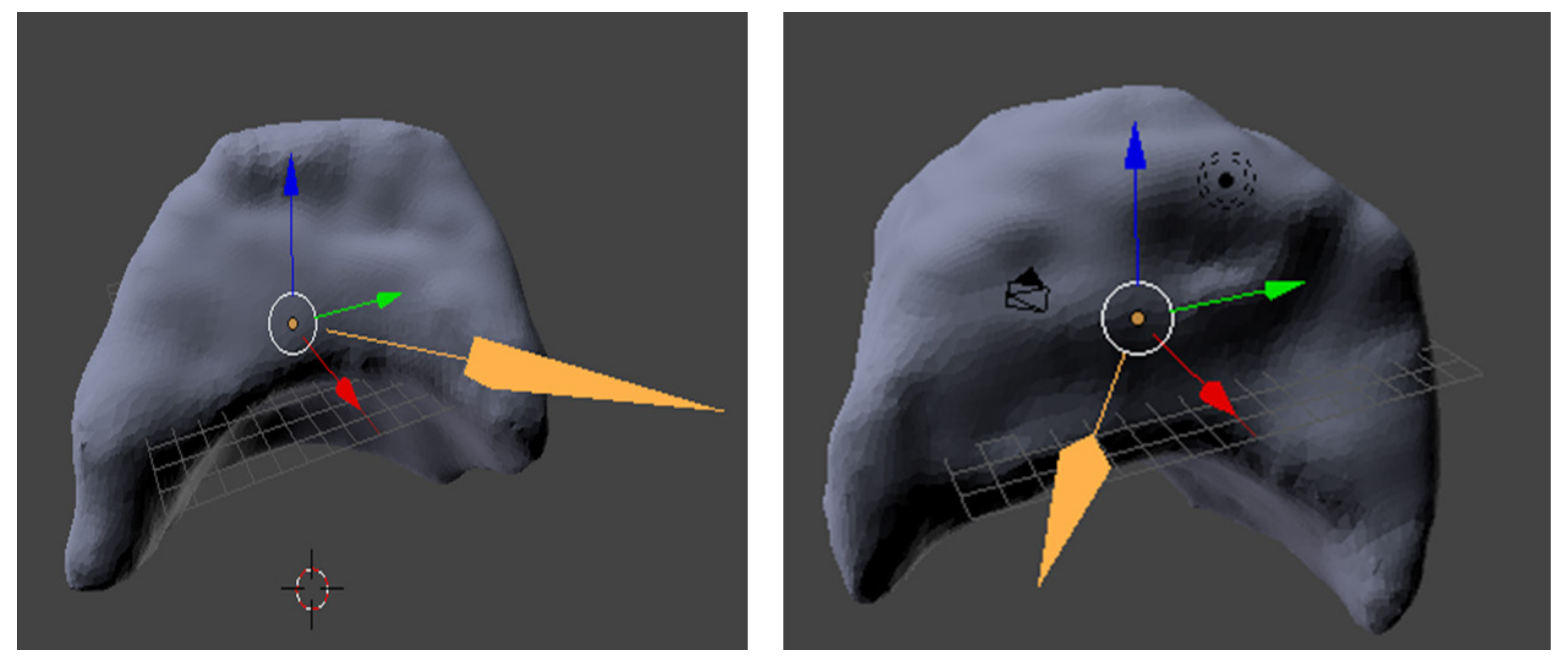

Figure 1. Lunate with the $1^{\text {st }}$ principal axis (yellow) with respect the fixed coordinate system X (red arrow), Y (green arrow), Z (blue arrow-direction of the CT-tomograph). Left-neutral position. Right-wrist extension.
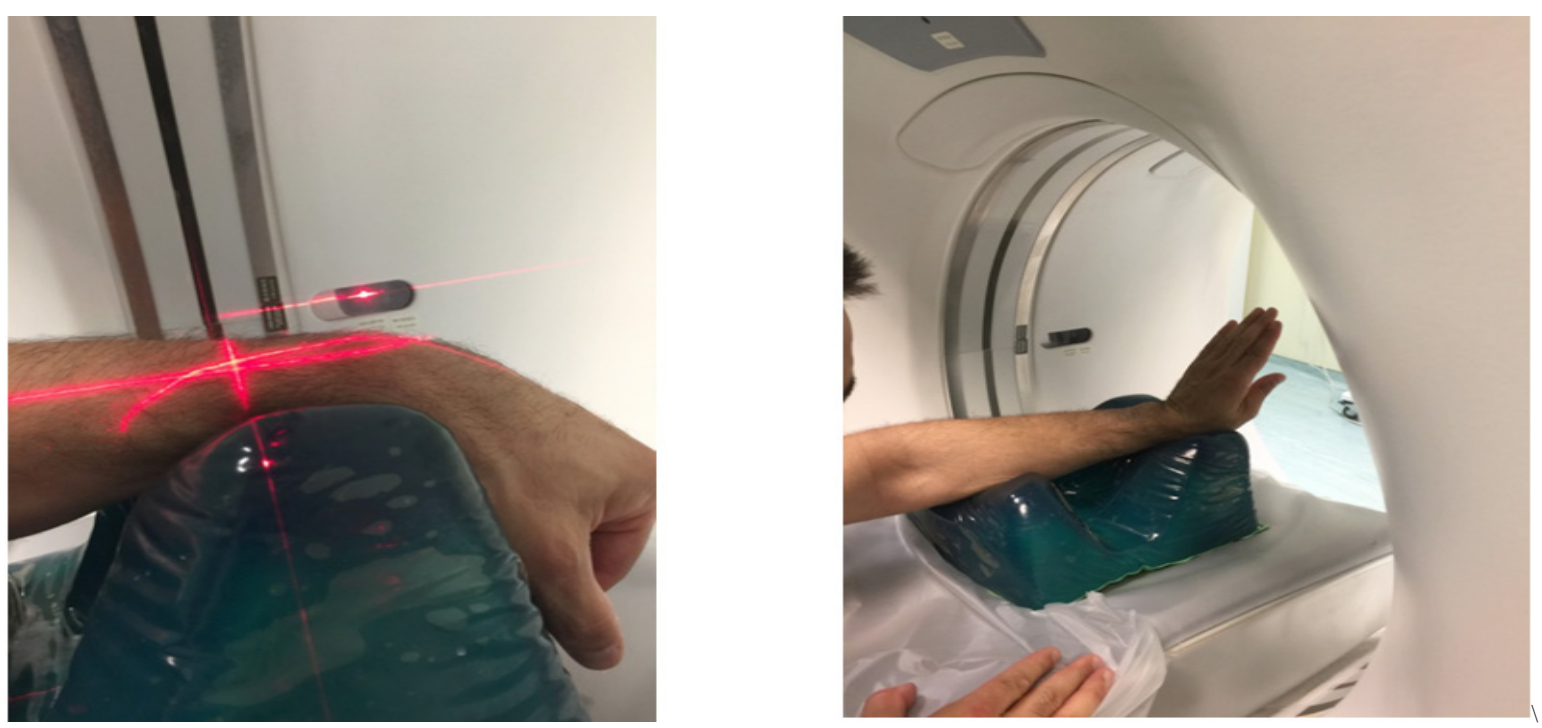

Figure 2. Wrist in flexion position (Left). Wrist in extension position. A special silicon base for the wrist (right) 

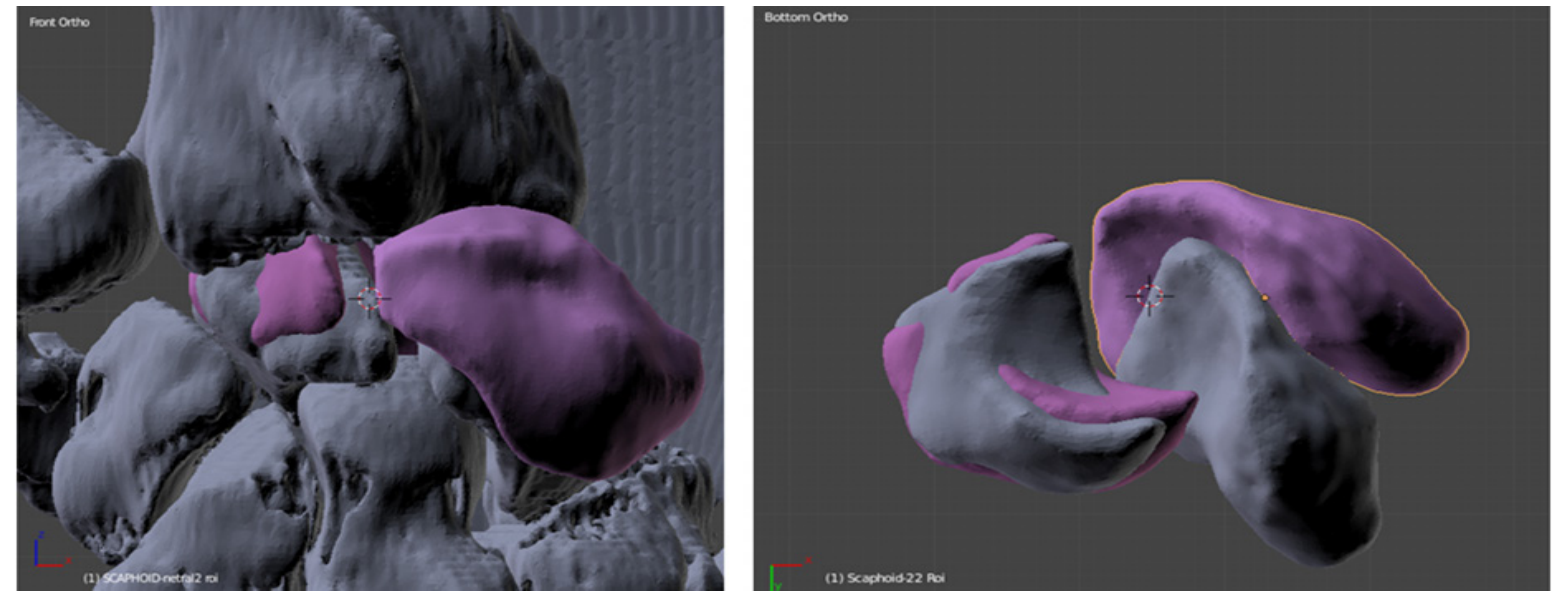

Figure 3. 3D reconstruction of the wrist. Hand in the neutral position. Sc and $\mathrm{L}$ are depicted also in extension (magenta). Frontal-palmar view, $\mathrm{Z}$ axis is the scanner table Axis (Left). Bone pairs of Sc and L in neutral (grey) to extension (magenta). View the capitate cavity. X-Y plane of the CT scanner coil (Right).

Thus the exact kinematic parameters of: a) the translation of the centroid, and b) the rotation of the principal axes system from the neutral and each of the extreme positions of the Sc and L bones are displayed in table 1.
Relative rotations of the principal axis within an error of $\pm 1^{\circ}$ and relative distances of the centroids within an error of $\pm 0.5 \mathrm{~mm}$ were calculated and are displayed in table 2 .

Table 1. Covariant analysis (Eigenvector, principal axes) for Sc \& $\mathrm{L}$ in each position of the wrist.

\begin{tabular}{|c|c|c|c|c|c|c|c|c|c|c|c|c|c|c|c|}
\hline & \multicolumn{3}{|c|}{$S c$ in $N p$} & \multicolumn{3}{|c|}{$\mathbf{S c}$ in $\mathbf{E} \mathbf{p}$} & \multicolumn{3}{|c|}{$S c$ in $F p$} & \multicolumn{3}{|c|}{ Sc in RD p } & \multicolumn{3}{|c|}{$S c$ in UD $p$} \\
\hline \multirow{2}{*}{$\begin{array}{l}1^{\text {st }} \mathrm{PA} \\
\text { EVect. }\end{array}$} & $\mathrm{X}$ & $\mathrm{Y}$ & Z & $\mathrm{X}$ & $\mathrm{Y}$ & Z & $\mathrm{X}$ & $\mathrm{Y}$ & $\mathrm{Z}$ & $\mathrm{X}$ & $\mathrm{Y}$ & $\mathrm{Z}$ & $\mathrm{X}$ & $\mathrm{Y}$ & $\mathrm{Z}$ \\
\hline & -0.474 & 0.718 & 0.509 & -0.568 & 0.015 & 0.822 & -0.400 & 0.916 & -0.021 & -0.503 & 0.815 & 0.285 & -0.349 & 0.634 & 0.689 \\
\hline $\begin{array}{l}2^{\text {nd }} P A \\
\text { EVect. }\end{array}$ & 0.100 & -0.531 & 0.841 & 0.193 & -0.969 & 0.151 & 0.008 & -0.019 & -0.999 & 0.264 & 0.460 & -0.847 & 0.176 & -0.678 & 0.713 \\
\hline \multirow[t]{2}{*}{$\begin{array}{l}3^{\mathrm{d}} \mathrm{PA} \\
\text { EVect. }\end{array}$} & 0.874 & 0.449 & 0.179 & 0.799 & 0.244 & 0.548 & -0.916 & -0.400 & -0.001 & -0.822 & -0.351 & -0.477 & 0.920 & 0.371 & 0.125 \\
\hline & \multicolumn{3}{|c|}{$L$ in $N p$} & \multicolumn{3}{|c|}{$\mathbf{L}$ in $\mathbf{E} p$} & \multicolumn{3}{|c|}{$L$ in $F p$} & \multicolumn{3}{|c|}{$L$ in $R D p$} & \multicolumn{3}{|c|}{$L$ in UD p } \\
\hline \multirow{2}{*}{$\begin{array}{l}1^{\text {st }} \mathrm{PA} \\
\text { EVect. }\end{array}$} & $\mathrm{X}$ & $\mathrm{Y}$ & Z & $\mathrm{X}$ & $\mathrm{Y}$ & $\mathrm{Z}$ & $\mathrm{X}$ & $\mathrm{Y}$ & $\mathrm{Z}$ & $\mathrm{X}$ & $\mathrm{Y}$ & Z & $\mathrm{X}$ & $\mathrm{Y}$ & $\mathrm{Z}$ \\
\hline & -0.542 & 0.767 & 0.341 & -0.610 & 0.639 & 0.467 & -0.604 & 0.795 & -0.039 & -0.476 & 0.879 & -0.014 & -0.435 & 0.650 & 0.622 \\
\hline $\begin{array}{l}2^{\text {nd }} P A \\
\text { EVect. }\end{array}$ & -0.701 & -0.637 & 0.319 & -0.715 & -0.698 & 0.019 & -0.706 & -0.512 & 0.487 & -0.863 & -0.464 & 0.198 & 0.642 & 0.708 & -0.291 \\
\hline $\begin{array}{l}3^{\mathrm{d}} \mathrm{PA} \\
\text { EVect. }\end{array}$ & 0.462 & -0.066 & -0.884 & 0.338 & -0.323 & 0.883 & 0.367 & 0.322 & 0.872 & 0.168 & 0.106 & 0.980 & -0.630 & 0.272 & -0.726 \\
\hline
\end{tabular}

Abbreviations: $\mathrm{PA}=$ Principal Axis, $\mathrm{Sc}=$ Scaphoid bone, $\mathrm{L}=$ Lunate bone, EVect. = Eigenvector, $\mathrm{N}=$ Neutral, $\mathrm{E}=$ Extension, $\mathrm{F}=\mathrm{Flexion}, \mathrm{RD}=\mathrm{Radial}$ Deviation of wrist, $\mathrm{UD}=\mathrm{Ulnar}$ Deviation of wrist, $\mathrm{p}=$ position.

For practical anatomic reasons and in order for the data to become more easily available to the radiologist and hand surgeon, additional information of the major principal axis for Sc and L bones is given with respect to the global fixed (X, Y, Z) reference system in table $3 \mathrm{a}$.

\section{The screw}

The FS Figure 4, was constructed from stainless steel 316, with $7.7 \mathrm{~mm}$ outer diameter, threaded step $1.3 \mathrm{~mm}$, core diameter $4.5 \mathrm{~mm}$, total length $20 \mathrm{~mm}$, spring length $3.2 \mathrm{~mm}$, spring coil length and outer diameter $0.8 \mathrm{~mm}$ and $6.5 \mathrm{~mm}$ respectively. The specifications kinematic data for extension and rotation of the flexible part of the screw are given in Tables 2-3.

The screw is surgically designed to be inserted in the neutral position in a predetermined path, along a straight line $\mathrm{ABCD}$ Figure 4, opened with guide drilling.

The $\mathrm{AB}$ and $\mathrm{CD}$ segment of the screw is inside the $\mathrm{Sc}$ and the $\mathrm{L}$ bone mass respectively. Obviously $\mathrm{BC}$ represents the flexible spring portion of the FS Figure 5, which lies in the mid joint space. 
Fotios Vasilios Nikolopoulos (2018) Kinematic Investigation, of a New Flexible Orthopedic Screw (Flexyscrew) for Repairing the Torn Scapholunate Ligament, with the Use of 3D-CT/Scan-Covariant Method and Demonstration on a 3D-Printed Model

Table 2a. Kinematic Study (relative solid angle) of the 1st Principal Axis in flexion, extension, radial \& ulnar deviation with respect to the initial neutral position of the wrist.

\begin{tabular}{|c|c|c|c|}
\hline & $\begin{array}{c}1^{\text {st }} \text { principal } \\
\text { axis in the } \\
\text { initial- } \\
\text { neutral } \\
\text { position }\end{array}$ & $\begin{array}{l}\text { 2nd Principal } \\
\text { axis in the } \\
\text { initial-neutral } \\
\text { position }\end{array}$ & $\begin{array}{l}\text { 3rd Principal } \\
\text { axis in the } \\
\text { initial-neutral } \\
\text { position }\end{array}$ \\
\hline $\begin{array}{l}1^{\text {st }} \text { principal axis of the } \mathrm{Sc} \text { in } \\
\text { Extension }\end{array}$ & $46^{\circ}$ & $49^{\circ}$ & $25^{\circ}$ \\
\hline $\begin{array}{l}1^{\text {st }} \text { principal axis of the } \mathrm{L} \text { in } \\
\text { Extension }\end{array}$ & $11^{\circ}$ & $18^{\circ}$ & $16^{\circ}$ \\
\hline $\begin{array}{l}1^{\text {st }} \text { principal axis of the } \mathrm{Sc} \text { in } \\
\text { Flexion }\end{array}$ & $33^{\circ}$ & $146^{\circ}$ & $169^{\circ}$ \\
\hline $\begin{array}{l}1^{\text {st }} \text { principal axis of the } \mathrm{L} \text { in } \\
\text { Flexion }\end{array}$ & $22^{\circ}$ & $12^{\circ}$ & $23^{\circ}$ \\
\hline $\begin{array}{l}1^{\text {st }} \text { principal axis of the } \mathrm{Sc} \text { in } \\
\text { radial deviation }\end{array}$ & $14^{\circ}$ & $159^{\circ}$ & $63^{\circ}$ \\
\hline $\begin{array}{l}1^{\text {st }} \text { principal axis of the } \mathrm{L} \text { in } \\
\text { radial deviation }\end{array}$ & $22^{\circ}$ & $15^{\circ}$ & $20^{\circ}$ \\
\hline $\begin{array}{l}1^{\text {st }} \text { principal axis of the } \mathrm{Sc} \text { in } \\
\text { ulnar deviation }\end{array}$ & $13^{\circ}$ & $12^{\circ}$ & $6^{\circ}$ \\
\hline $\begin{array}{l}1^{\text {st }} \text { principal axis of the } \mathrm{L} \text { in } \\
\text { ulnar deviation }\end{array}$ & $19^{\circ}$ & $175^{\circ}$ & $162^{\circ}$ \\
\hline
\end{tabular}

Table 2b. Centroid distances in different wrist positions.

\begin{tabular}{|l|c|}
\hline \multicolumn{2}{|c|}{$\begin{array}{c}\text { Distances between the centroids of the Sc and } \mathbf{L} \\
\text { bones (+- 0.5mm) }\end{array}$} \\
\hline neutral & 17.9 \\
\hline flexion & 16.9 \\
\hline extension & 19.5 \\
\hline radial deviation & 19.4 \\
\hline neutral & 17.9 \\
\hline
\end{tabular}

As the Sc-L joint moves from the neutral to each of the extreme positions the middle spring of the FS deforms and flexes, following the motion of the bones.

The STL files were prepared for 3D printing with freeCad. Holes were opened on the bone volumes files, for the FS insertion and the $1^{\text {st }}$ principal axis table 1 . Subsequently the Sc and L bone STL files, were printed with ABS plastic material in a Zortax M200 3D printer. A $\mathrm{k}$-wire was inserted through the $1^{\text {st }}$ principal axis hole (see black arrow Figure 6a). Then the FS was screwed through the already opened hole (see red arrow Figure 6a).
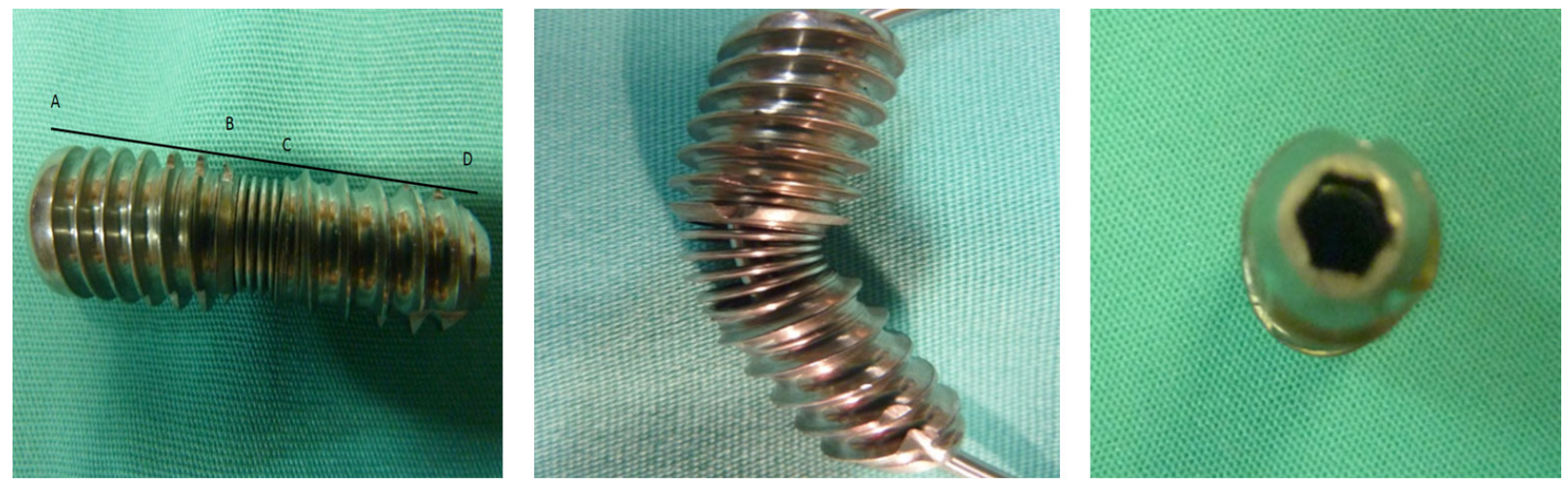

Figure 4. The Flexible screw (FS). AB and CD the solid screwed part of the FS. Note that the midportion BC (the spring) is without any deformation (left). A k-wire has inserted through the cannulated FS in order to depict the flexibility (middle). FS in detail-Hexagonal cross section of the core for the insertion of the guide wire $\&$ the screw driver (right).
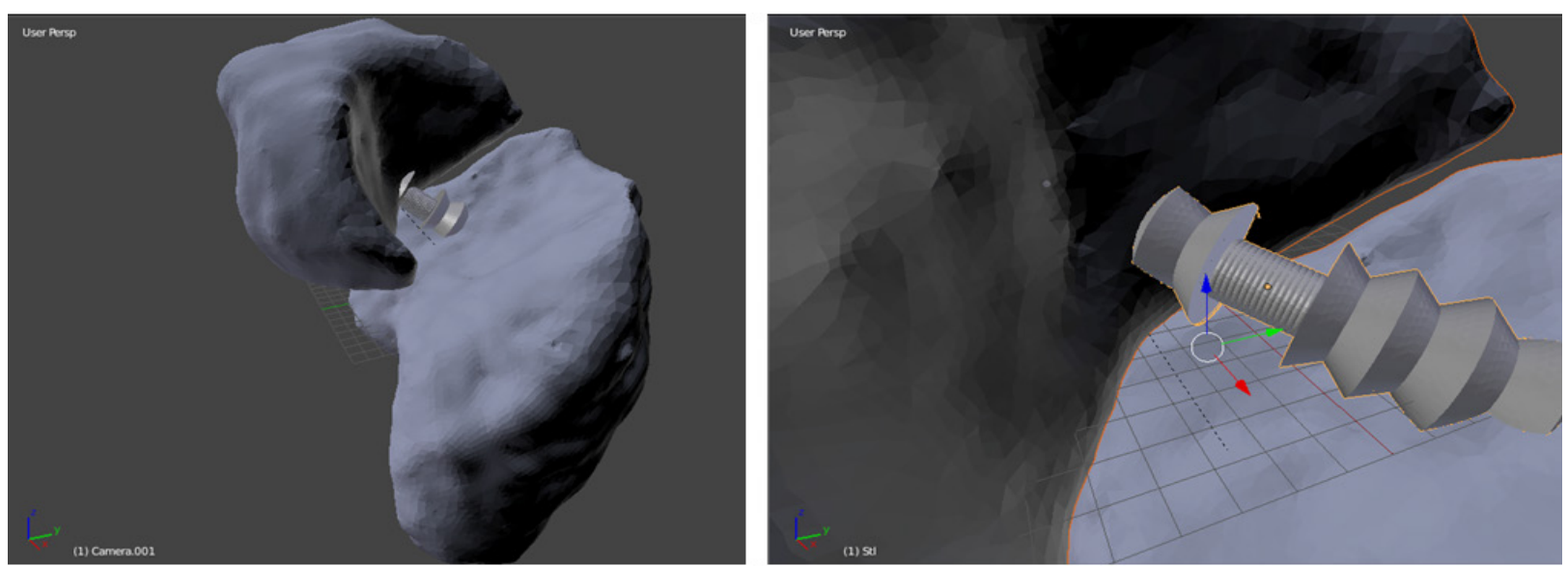

Figure 5. The Flexyscrew and the spring in the Sc-L midjoint space in the neutral position from STL files processed (left). Detail of the Flexyscrew and the spring in the Sc-L midjoint in neutral position: from the capitate cavity (right). 

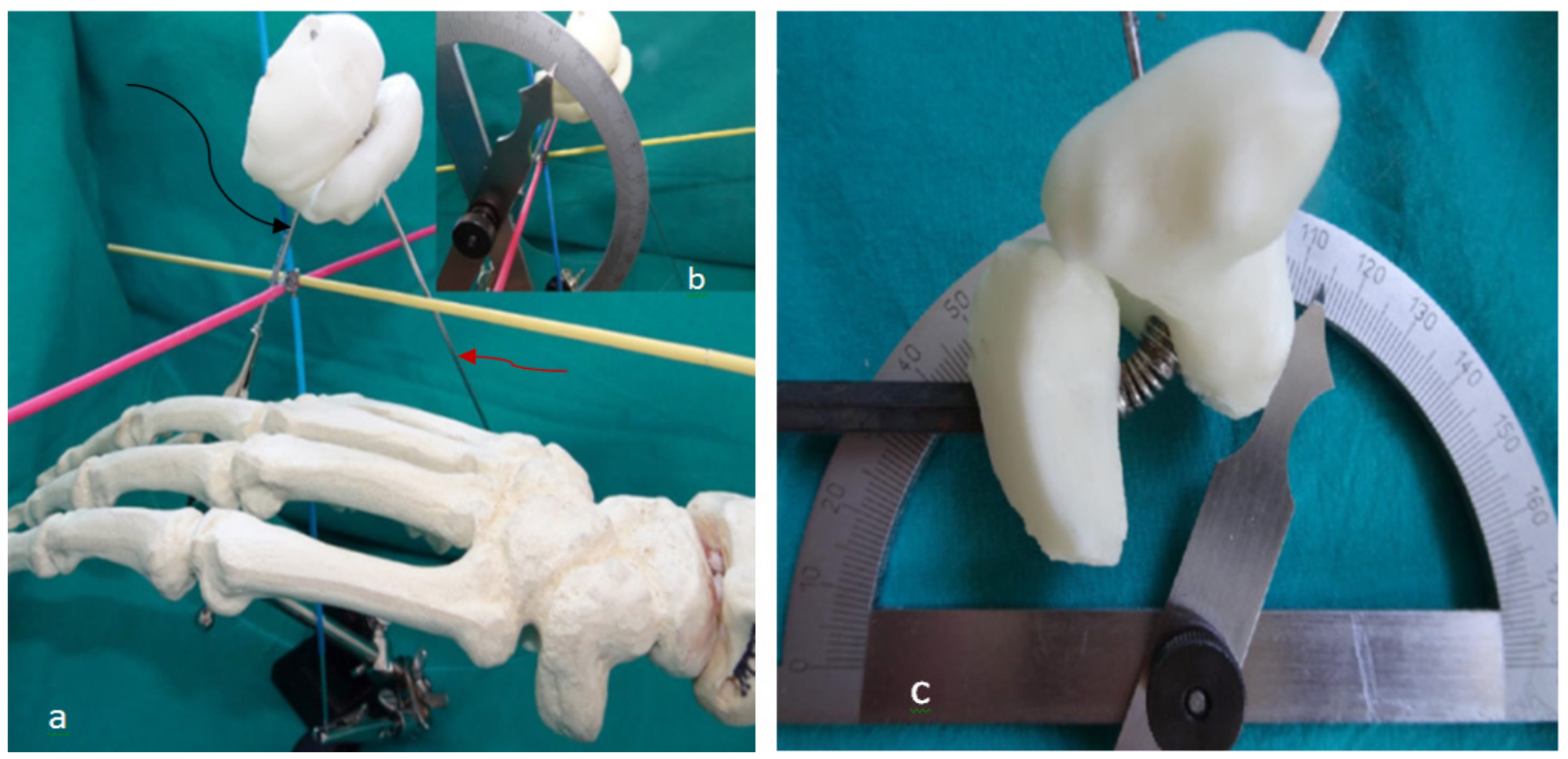

Figure 6. (a)Hand posture in neutral position. Yellow: Z-axis of the CT/table, red: X-axis, blue: Y-axis. Black arrow: 1st principal axis of the Sc, red arrow: axis of the FS in neutral position. Detail (b) the 1 st principal axis with y-axis at $44^{\circ}$ (see Table 3a). (c) The spring can deform and flex over $180-110=70^{\circ}$ degrees easily attainable in all directions. Therefore can satisfy all the calculated values of the Table $3 \mathrm{~b}$.

\section{Results}

\section{Biometric data from covariant analysis}

Eigenvectors for each of the three principal axes, of the Sc and L obtained from the covariant analysis are given in Table 1.

\section{Translation of the bones}

The centroids in radial and extension have maximum displacement of almost $19 \mathrm{~mm}$ but generally we don't have big centroid displacements from the initial neutral position which is approximately $17.9 \mathrm{~mm}$.

\section{Rotation of the bones (relative \& absolute)}

In order to describe and analyze the actual kinesiology of the two bones in the extreme positions of the wrist, specifically for the rotation of the bones, the relative solid angles of the $1^{\text {st }}$ principal axis, with respect to the neutral position, are presented in Table $2 \mathrm{a}$. The $2^{\text {nd }}$ and $3^{\mathrm{d}}$ principal axes are perpendicular-orthogonal to the $1^{\text {st }}$ principal axis and thus omitted for simplicity reasons.

Concerning the absolute rotations of the bones the $1^{\text {st }}$ principal axis with respect to XYZ global reference system angles are presented in Table 3a.

The Sc-L 3D printed model complex was placed in the XYZ fixed wire system, ( $\mathrm{Z}$ is the axis of the $\mathrm{CT} /$ table). The $1^{\text {st }}$ principal axis in $44^{\circ}$ angle with the $\mathrm{Y}$ axis, and the $\mathrm{z}$-axis (axis of the CT/scan table) is almost collinear $\left(1.5^{\circ}\right)$ with the $1^{\text {st }}$ principal axis in neutral position being depicted in Figure $6 \mathrm{~b}$.

\section{The FS}

The FS is inserted in a straight line (ABCD) Figure 4, entering from the Sc entry point to the $\mathrm{L}$ bone as defined from the guide $\mathrm{k}$-wire. Our kinematic analysis gives the transformation CD solid part into the $\mathrm{L}$ in relation to $\mathrm{AB}$ solid screw part into the Sc. Maximum angles between the solid parts of the FS were found to be $53.5^{\circ}$ and $33.5^{\circ}$ (see Table $3 \mathrm{~b}$ ) for ulnar and radial deviation and $35^{\circ}$ and $23^{\circ}$ for flexion and extension, respectively.

Maximum displacements of the spring BC is $1.68 \mathrm{~mm}$ Table $3 \mathrm{~b}$ in radial deviation. Small compression of the spring in ulnar deviation is $-0.24 \mathrm{~mm}$. For extension and flexion the spring dimension does not alter significantly within experimental error.

\section{The 3D-printed model}

The 3D-printed model of the Sc-L joint with the screw embodied (Figure 6) was studied by visual inspection with the help of a protractor. In the extreme 4 positions of the wrist, flexion, extension, radial and ulnar deviation, the corresponding FS solid parts $\mathrm{AB}$ and $\mathrm{CD}$ are displaced and rotated following the kinematics of the Sc and $\mathrm{L}$ bones. It is obvious from Figure $6 \mathrm{c}$ that the FS makes an easy rotation of $70^{\circ}$, a value which is well over the maximum deflection of $53.5^{\circ}$ for ulnar deviation as obtained in Table $3 \mathrm{~b}$.

\section{Discussion}

Various kinematic methods are offered in literature for the description of the scaphoid and lunate, such as a) coordinate Measuring Machine b) simple radiologic study with X-rays [14] c) markers in wrist cadavers recorded by stereoradiography [15] d) CT/scan tomography [16]. Other investigators exploit principal axis registration method and Helical Axis Motion parameters (HAM) [17]. Recent literature studied carpal kinematics using 3D-CT/scan. Snel, J.G et al [18] used the Finite Helical Axis (FHA) and registration techniques for the kinematics of the wrist and give data for the capitate bone. In the present work, we use covariant analysis for obtaining the principal axis of individual bones which is more practical for voxelized solids. 
Fotios Vasilios Nikolopoulos (2018) Kinematic Investigation, of a New Flexible Orthopedic Screw (Flexyscrew) for Repairing the Torn Scapholunate Ligament, with the Use of 3D-CT/Scan-Covariant Method and Demonstration on a 3D-Printed Model

Table 3a. Angles of the Major, $1^{\text {st }}$ Principal Axis, for Sc \& L bone with respect to the global or reference axis X.Y, Z. Z is the longitudinal axis of the CT scanner table. (N.=Neutral, Flex.=Flexion, Ext.=Extension, Rad. D=Radial Deviation, Uln. D=Ulnar Deviation).

\begin{tabular}{|c|c|c|c|c|c|c|c|c|c|c|c|c|c|c|c|}
\hline & \multicolumn{5}{|c|}{$\begin{array}{c}\text { Angle of 1st Principal Axis } \\
\text { with } \mathrm{x} \text {-Axis }\end{array}$} & \multicolumn{5}{|c|}{$\begin{array}{c}\text { Angle of 1st Principal Axis } \\
\text { with y-Axis }\end{array}$} & \multicolumn{5}{|c|}{$\begin{array}{c}\text { Angle of 1st Principal Axis } \\
\text { with z-Axis }\end{array}$} \\
\hline & N. & Flex. & Ext. & Rad. D. & Uln. D. & N. & Flex. & Ext. & Rad. D & Uln. D & N. & Flex. & Ext. & Rad. D. & Uln. D. \\
\hline Scaphoid & $118^{\circ}$ & $114^{\circ}$ & $125^{\circ}$ & $120^{\circ}$ & $111^{\circ}$ & $44^{\circ}$ & $24^{\circ}$ & $89^{\circ}$ & $35^{\circ}$ & $51^{\circ}$ & $1.5^{\circ}$ & $91^{\circ}$ & $35^{\circ}$ & $73^{\circ}$ & $46^{\circ}$ \\
\hline Lunate & $123^{\circ}$ & $127^{\circ}$ & $128^{\circ}$ & $119^{\circ}$ & $116^{\circ}$ & $40^{\circ}$ & $37^{\circ}$ & $50^{\circ}$ & $28^{\circ}$ & $49^{\circ}$ & $70^{\circ}$ & $92^{\circ}$ & $62^{\circ}$ & $91^{\circ}$ & $52^{\circ}$ \\
\hline
\end{tabular}

Table 3b. Angles between shafts AB and CD and spring elongation of the FS in the extreme positions of the wrist.

\begin{tabular}{|c|c|c|c|c|c|c|c|c|c|}
\hline $\begin{array}{c}\text { Angle AB-CD } \\
\text { in neutral } \\
\text { (degrees) }\end{array}$ & $\begin{array}{c}\text { Angle } \\
\text { AB-CD in } \\
\text { flexion } \\
\text { (degrees) }\end{array}$ & $\begin{array}{c}\text { Angle AB-CD } \\
\text { in ext. } \\
\text { (degrees) }\end{array}$ & $\begin{array}{c}\text { Angle AB-CD } \\
\text { in radial D. } \\
\text { (degrees) }\end{array}$ & $\begin{array}{c}\text { Angle AB-CD } \\
\text { in ulnar D. } \\
\text { (degrees) }\end{array}$ & $\begin{array}{c}\text { Spring } \\
\text { Elongation in } \\
\text { neutral } \\
(\mathrm{mm})\end{array}$ & $\begin{array}{c}\text { Spring } \\
\text { Elongation in } \\
\text { flexion } \\
( \pm 0.5 \mathrm{~mm})\end{array}$ & $\begin{array}{c}\text { Spring } \\
\text { Elongation in } \\
\text { extension } \\
( \pm 0.5 \mathrm{~mm})\end{array}$ & $\begin{array}{c}\text { Spring } \\
\text { Elongation in } \\
\text { radial } \mathbf{D} . \\
( \pm \mathbf{0 . 5} \mathbf{~ m m})\end{array}$ & $\begin{array}{c}\text { Spring } \\
\text { Elongation in } \\
\text { ulnar D. } \\
( \pm \mathbf{0 . 5} \mathbf{~ m m})\end{array}$ \\
\hline 0 & 35 & 23 & 33.5 & 53.5 & 0 & 0.03 & 0.03 & 1.68 & -0.24 \\
\hline
\end{tabular}

\section{Sc-L kinematics}

Short et al [19] in 24 cases, found that when the wrist extends $30^{\circ}$, the scaphoid extends approximately $20^{\circ}$. In the same position the lunate extends about $12^{\circ}$. During wrist $50^{\circ}$ flexion, the scaphoid flexes about $35^{\circ}$ and the lunate flexes about $25^{\circ}$. The relative motion between these two bones was about $8^{\circ}$ to $10^{\circ}$.

In another study [20], during maximum flexion of the wrist the scaphoid extends about $28.2^{\circ}$ and the lunate extends about $17.6^{\circ}$ for the same position.

Litchman stated that scaphoid and lunate "bind the proximal row into a unit of rotational stability". Thus in radial and ulnar deviation the amount of intercarpal rotation allowed by the system is approximately $4^{\circ}$ at the scapholunate joint. However in flexion and extension, there can be as much as $30^{\circ}$ at the scapholunate joint" [21].

Julio [22-23] stated that "from neutral to dorsiflexion, the lunate rotates approximately $28^{\circ}$ and the scaphoid $30^{\circ}$. From neutral to complete volarflexion the lunate rotates $30^{\circ}$ and the scaphoid $60^{\circ}$. From these studies, it is understood that the rotation between the bones, relative to each other, is maximum $30^{\circ}$. Therefore, for their design implants criteria, relative rotation of the leading edge and trailing edge was set to $30^{\circ}$ maximum.

On average the scaphoid extends about $50^{\circ}$ and flexes about $58^{\circ}$, supinates about $6^{\circ}$ and deviates about $4^{\circ}$ in radial direction from start to finish. The lunate extends about $38^{\circ}$, pronates $5^{\circ}$ and deviates $3^{\circ}$ when the wrist moves from the neutral position. During radial deviation, the lunate flexes about $11^{\circ}$, radially deviates about $8.6^{\circ}$ and pronates about $6^{\circ}$. During ulnar deviation of the wrist, the lunate extends $32^{\circ}$, ulnarly deviates about $16^{\circ}$ and supinates about $5^{\circ}$ [24].

For clinical purposes, estimation of physiological limits of Sc and $\mathrm{L}$ movements and positions is mainly based on $2 \mathrm{D} \mathrm{x}$-ray analysis, as a more empirical and convenient method for practical reasons. The Lunate during flexion of the wrist flexes and demonstrates an angle of $50^{\circ}$ with the axis of the radius. During extension the $\mathrm{L}$ also extends and forms an angle of $35^{\circ}$ [25]. The average Sc-L angle in full flexion is $76^{\circ}$ and decreases in $35^{\circ}$ in full extension [26].
Ruby et al [27] finds that from full radial to full ulnar deviation the $\mathrm{Sc}$ rotates $51^{\circ}$ and the $\mathrm{L}$ rotates $35^{\circ}$ in contrast with Horri et al who could not find such differences among the two bones and gives an average of $36^{\circ}, 38^{\circ}$ for the Sc and L respectively.

Normal carpal bone motion with respect to the radius, is also measured by means of biplanar radiographic apparatus and gives in HAM representation, angles for the Sc $55^{\circ}, 56.1^{\circ}, 12.8^{\circ}, 22,7^{\circ}$ from neutral to flexion, extension, radial deviation and ulnar deviation respectively. For the $\mathrm{L} 45.1^{\circ}, 31.2^{\circ}, 13^{\circ}, 25.4^{\circ}$ from neutral to flexion, extension, radial deviation and ulnar deviation respectively [28]. Kobayashi,[15] gives for the carpal bone motion relative to the radius, for the Sc $40^{\circ}, 52^{\circ}, 4^{\circ}, 17^{\circ}$ and for the $\mathrm{L} 23^{\circ}, 30^{\circ}, 2^{\circ}, 22^{\circ}$ mean values for flexion, extension, radio-ulnar deviation respectively. The Sc and $\mathrm{L}$ bones are rotating around an axis which coincides with the dorsal portion of the Sc-L ligament assumed as the axis of Sc-L joint rotation forming a Sc-L angle $62^{\circ}$ and $27^{\circ}$ for flexion and extension of the wrist respectively [29].

Upal gives a rotation for the Sc $51.1^{\circ}$ in a mixed flexed position (with supination) and $89.9^{\circ}$ for a mixed extended position (with pronation) and for the $\mathrm{L} 52^{\circ}$ and $81.3^{\circ}$ respectively.

Since the different investigators do not use the same kinematic frames of reference and analyses, it is difficult to make an effective comparison between their respective studies. Furthermore, the meaning of individual matrix elements may be obvious but it is often difficult to visualize body attitude when all matrix elements are applied.

Concerning the classic literature's $\mathrm{Sc}-\mathrm{L}$ angle in one dimension radiographic plane, our result for this angle is $35^{\circ}$ Table $3 \mathrm{~b}$ for flexion and $23^{\circ}$ in extension of the wrist and as already mentioned this angle represents also the angle between the axes through the two solid parts of the flexyscrew AB-CD.

The $\mathrm{Sc}$ also rotates more than the $\mathrm{L}$ in flexion and extension as seen from the $1^{\text {st }}$ principal axis angles Table 2a.

On the other hand in radial and ulnar deviation, the L performs larger rotation than the Sc. Rotations of the bones for extension and flexion are found to be larger than those of the two deviations. 
Fotios Vasilios Nikolopoulos (2018) Kinematic Investigation, of a New Flexible Orthopedic Screw (Flexyscrew) for Repairing the Torn Scapholunate Ligament, with the Use of 3D-CT/Scan-Covariant Method and Demonstration on a 3D-Printed Model

The large differences observed among all investigators can be explained by the fact that the motion of the bones in the 3D-space differs from the $2 \mathrm{D}$ projection on the radiographic plate. Radiographic images are normal projections of the $3 \mathrm{D}$ positions of the bones. In addition radiographic data is obtained by drawing lines from anatomic landmarks of the external surface of the bones and not axes passing through the centroids as in our 3D analysis. Our reported angles, as expected, are larger than those obtained from the radiographic data, since our values refer to the epicenter and are not inscribed angles.

\section{Length of the Flexible section}

In an intact wrist, the average distance between scaphoid and lunate is approximately $1.6 \mathrm{~mm}$ in maximum flexion and $1.2 \mathrm{~mm}$ in maximum ulnar deviation [30]. The max elongation of the FS spring as shown in Table $3 \mathrm{~b}$ is $1.68 \mathrm{~mm}$ in radial deviation and there is a small compression $-0.24 \mathrm{~mm}$ in ulnar deviation. Otherwise minimal elongations of the spring are observed in flexion and extension.

As a general comment from Table $2 \mathrm{~b}$ we can infer that the bones do not translate a lot, but instead rotate almost perfectly about their centroids as is expected from a well functional joint with minimal friction.

\section{D-printed and FS-model}

By visual inspection of the $3 \mathrm{D}$ printed Sc-L model, the joint was not found to be obstructed by the flexible spring part of the FS. Also the maximum reported angle between the two solid parts of the screw $\mathrm{AB}-\mathrm{CD}$ were found to be $53.5^{\circ}$, a value that is easily attainable from the FS as shown in Figure 6. The maximum spring extension of \pm 2 $\mathrm{mm}$ due to centroid displacements of the Sc and L were found to be technically possible in the construction of the FS.

Finally, the main pearls of the FS could be summarized as:

a. FS is not disturbing the Sc-L joint movement.

b. The spring allows the relative motion, translation and rotation of Sc and L closer to the physiological motive.

c. The insertion technique is simple for the hand surgeons since uniaxial insertion can replace the cumbersome and problematic difficult operations for Sc-L instability.

Concerning our kinematic method could be extended and easily applied to any other joint in order to provide technical specifications for custom made FS.

\section{References}

1. Apergis M (2013) Fractures-dislocations of the wrist. (1stedn), Springer-Verlag, Italy Pg No: 223-295.

2. Cooney PW, Linscheid LR, Dobyns HJ (1998) The Wrist: Diagnosis and Operative Treatment. In: Cooney PW, Linscheid LR, Dobyns HJ (eds.). (1 stedn), Mosby Publisher, Missouri, USA Pg No: 501-524.

3. Rosenwasser MP, Miyasajsa KC, Strauch RJ (1997) The RASL procedure: reduction and association of the scaphoid and lunate using the Herbert screw. Tech Hand Up Extrem Surg 1: 263-272. [crossref]

4. Budoff JE (2008) Treatment of acute lunate and perilunate dislocations. J Hand Surg Am 33: 1424-1432. [crossref]

5. Acumed - Acutrak $2 ®$ Standard. Available from: http://www.acumed.net/ product $/ 19$. Accessed January 11 th 2008 .

6. Sucec MC, Tuller TC (2006) Bone Connector with Pivotable Joint. United States Patent US 20060271054
7. Kabir S (2008) Flexible Screw Design for Bone Implant Application [Thesis]. Virginia Commonwealth University.

8. Nikolopoulos F, Kefalas V (2013) Orthopedic Screw. Greece Patent GR 1008012

9. Nikolopoulos F, Kefalas V (2015) Orthopedic Screw. Greece Patent GR 1008431.

10. Nikolopoulos F, Kefalas V (2018) Orthopedic Screw with tool of insertion. Greece Patent GR 1009280.

11. Nikolopoulos F, Kefalas V (2017) Kinematic Analysis of a Flexible Orthopedic Screw (FlexyScrew) with the Use of CT/scan 3D Reconstruction and Technique Demonstration for Repairing the Scapholunate Rupture of the Wrist. 28th Annual Meeting of the European Society for Biomaterials. Megaron Athens International Conference, Athens, Greece.

12. Nikolopoulos F, Poulilios A, Vidalis G, Kefalas V (2015) A New Screw and Technique for the Treatment of Ruptured Multiaxial Joint Ligaments: A Preliminary Study on the Scapholunate Dissociation of the Wrist. PeerJ PrePrints 3: 810v1.

13. Nikolopoulos F, Apergis E, Kefalas V, et al (2011) Biomechanical Properties of the Scapholunate Ligament and the Importance of its Portions in the Capitate Intrusion Injury. Clinical Biomechanics 26: 819-823.

14. Schernberg F (1990) Roentgenographic examination of the wrist: a systematic study of the normal, lax and injured wrist. Part 1: The standard and positional views. $J$ Hand Surg Br 15: 210-219. [crossref]

15. Kobayashi M, Berger RA, Nagy L, et al (1997) Normal kinematics of Carpal Bones: A Three Dimensional Analysis of Carpal Bone Motion Relative to the Radius. $J$ Biomech 30: 787-793.

16. Crisco JJ, McGovern RD (1998) Efficient Calculation of Mass Moments of Inertia for Segmented Homogenous Three-dimensional Objects. J Biomech 31: 97-101.

17. Upal MA (2003) Carpal Bone Kinematics on Combined Wrist Joint Motions May Differ From the Bone Kinematics During Simple Wrist Motions. Biomed Sci Instrum 29: 272-277.

18. Snel JG, Venema HW, Moojen TM, Ritt JP, Grimbergen CA, et al (2000) Quantitive in Vivo Analysis of the Kinematics of Carpal Bones from Three-Dimensional CT Images Using a Deformable Surface Model and a Three-Dimensional Matching Technique. Med Phys 27: 2037-2047.

19. Short WH, Werner FW, Fortino MD, Mann KA (1997) Analysis of the kinematics of the scaphoid and lunate in the intact wrist joint. Hand Clin 13: 93-108. [crossref]

20. Werner FW, Short WH, Green JK (2005) Changes in Patterns of Scaphoid and Lunate Motion During Functional Arcs of Wrist Motion Induced by Ligament Division. J Hand Surg 30: 1156-1160

21. Lichtman DM (1988) The Wrist and its Disorder. Philadelphia: W.B. Saunders Company Pg No:14-45.

22. Taleisnik J (1985) The Wrist. New York: Churchill Livingstone Pg No: 3-25.

23. Walsh JJ, Berger RA, Cooney WP (2002) Current Status of Scapholunate Interosseous Ligament Injuries. Journal of the American Academy of Orthopaedic Surgeons 10: 32-42.

24. Cooney PW, Linscheid LR, Dobyns HJ (1998) The Wrist: Diagnosis and Operative Treatment. In: Cooney PW, Linscheid LR, Dobyns HJ (eds.). (1stedn), Mosby Publisher, Missouri, USA Pg No: 501-526.

25. Schmidt HM, Lanz U (2004) Surgical Anatomy of the Hand. (1stedn), New York: Thieme Pg No: 76.

26. Cooney PW, Linscheid LR, Dobyns HJ (1998) The Wrist: Diagnosis and Operative Treatment. In: Cooney PW, Linscheid LR, Dobyns HJ (eds.). (1stedn), Mosby Publisher, Missouri, USA Pg No: 212.

27. Ruby LK, Cooney WP 3rd, An KN, Linscheid RL, Chao EY (1988) Relative Motion of Selected Carpal Bones: A Kinematic Analysis of the Normal Wrist. $J$ Hand Surg 13: 1-10.

28. Horii E, Garcia-Elias M, An KN, et al (1991) A kinematic study of luno-triquetral dissociation. J Hand Surg 16: 355-362.

29. Ritt MJ, Linscheid RL, Cooney WP, Berger RA, An KN (1998) The Lunotriquetral Joint: Kinematic Effects of Sequential Ligament Sectioning, Ligament Repair, and Arthrodesis. J Hand Surg Am 23: 423-445.

30. Short WH, Werner FW, Green JK, Masaoka S (2002) Biomechanical evaluation of ligamentous stabilizers of the scaphoid and lunate. J Hand Surg Am 27: 991-1002. [crossref]

Citation:

Nikolopoulos FV, Efthymiadis NC, Kefalas VA(2018) Kinematic Investigation, of a New Flexible Orthopedic Screw (Flexyscrew) for Repairing the Torn Scapholunate Ligament, with the Use of 3D-CT/Scan-Covariant Method and Demonstration on a 3D-Printed Model. Integr J Orthop Traumatol Volume 1(1): $1-7$. 